\title{
Neurofibromatosis type 1
}

INSERM

\section{Source}

INSERM. (1999). Orphanet: an online rare disease and orphan drug data base.

Neurofibromatosis type 1. ORPHA:636

Neurofibromatosis type 1 (NF1) is a clinically heterogeneous, neurocutaneous genetic disorder characterized by café-au-lait spots, iris Lisch nodules, axillary and inguinal freckling, and multiple neurofibromas. 